ECOLOGICAL PSYCHOLOGY, 7(4), 375-378

Copyright (1) 1995, Lawrence Erlbaum Associates, Inc.

COMMENTARIES ON KEYNOTE PRESENTATION III

\title{
Affordances and the Practice of Industrial Design Engineering: Comments on Smets's Presentation
}

\author{
Ad W. Smitsman \\ Department of Psychology \\ University of Nijmegen
}

A question that struck me when reading Gerda Smets's (this issue) article on industrial design engineering is how the ecological theory of perception and action and especially the study of affordances may contribute to the practice of industrial design engineering. Manufactured products are made to be perceived and to invoke behavior by being perceived. Such goals require that the products of industrial deargn be meaningful to behavior, that is, that they provide the user with opportunities for discovering and exploiting affordances. Affordances are the kind of properties that are or should be at the core of such products. However, I see a problem, namely, how to define and measure the affordances: that those products are designed to provide.

Studies such as those on the perception of the affordances of riser heights of stairs (Mark, 1987; Warren, 1984) and the affordances of the width of door openings (Warren \& Whang, 1987) suggest that affordances are confined to the individual products themselves. Such a narrow focus on the individual product is problematic for understanding the tools that many of the products of industrial design, in fact, are. Let me clarify this point by taking a few examples. 
from everyday life, namely, the examples of spons and chairs. Research on particlpants" perception of the affordance of doot openings and riser heights suggests that what counts as the affordance are the dimensions of nisers and door openings that fit the relevant body dimensions for clinting and passing through. When we apply this insight to spioon's and chairs, we would expect that spoons are meaningful for behavior to the extent that they can be grasped and held by the hand, and chairs, to the extent that they afford comfortable sitting. This is obviously not true for groons and, to some extent, also not for chatrs. There are many objects that can be confortably held but are nevertheless useless for eating. There are chairs that can hardly be comfortably sat upon but that ane nevertheless loved by their owners because they mean something to the behavior of their owners. For example a pianist needs a chair that enables his or her atms and shoulders to be free from perturbing forces; but such a chair would provide little comfort for sitting, especially in the absence of alkeyboard that the planist touches while sitting. Tools such as spoons are designed not only to be helid by the hand but also to transport food in a culturally acceptable way. These examples show: that the study of affordances of oljects not only concerns the relation of the object to the user but also the relation of the object to other parts of the environment in which use of the object is mbedded, Moreover; the trelation of user to the environment mais be changed when an object formis part of the effectivities of the user, and as a congequence, new opportunities arise for the discovery of niew affordances.

Fruiktull use of the affordance concept requires us to think through the changing relation between the organism and the enwiromment. The ecological theory of perception and action views the oxganism and the environment as mutually related parts of one uniffed system. Nevertheless, the organism is treated as separated from the environment by a strict boundary of its receptor surfaces and skin. This boundary is taken for granted. However, the ecological psychology that, for example, Gibson was working on conceived of the organisin as separated from the environment by a less fixed and stable boundary (see Gibson, 1979). In fact, the boundary may change continuously and momentarily. This can easily be shown by a very simple example of object manipula. toon. Any hand-held rod, even when grasped just to carry it to another place, will cause metric and kinetic changes in the prehensile system as a whole. When functional effective action modes emerge on the basis of kinetic and metric properties of the action system and task demands, new action modes may arise or loss of existing action modes may oceur because of the way a handiheld rod has instantaneously changed the system. Hand-held objects and even the objectis we sit on become part of our body just by holding them and sitting on them. These activities change the boundary of environment and organism. At the level of behaviord organization and control, there exist not an anatomical but a functional boundary between organisim and environment. What belonged 
to the environment may instantaneously and momentarily become part of the organism.

What are the consequences of this view of the organism for the way we should look at the affordances of objects, especially manufactured objects? The answer is that we should look at manufactured objects as products that are made to change the body and the action modes of an actor. The affordances they offer are not just what the products themselves mean to behavior but also what the environment means to a momentarily changed organism when the product becomes part of the body. How different the affordances are that may be discovered when action modes are differently changed can be illustrated by a discussion between two children that I overheard years ago. Both children had arrived at the same place, a French harbor on the Normandy coast. One child had arrived at this place by sailing along the coast in a small boat. It took her many days to arrive; strong winds, seasickness, wet suits, and other discomforts had to be overcome on a sailboat in the North Sea. The other girl had traveled by car and had spent only a few hours (albeir boring ones) in traveling to the same place. The two girls talked about what their experiences were, how far away they were from home, and the efforts that would be needed to return. Their discussion focused on the different affordances they discovered while traveling, that is, what the distance from home meant to them. This meaning was so different that it was difficult for them to understand each other. The affordances they had discovered were not what the vehicles they had used meant to behavior but what the environment had offered them when these vehicles changed their effectivities for travel.

Out view of manufactured products can be obscured not only by the way we conceive of the organism, but also by the way we conceive of the environment and objects. Products are manufactured to be used. The attractiveness of their shape and color may be one aspect that is of interest, but their function is another one. A function is not something that an object owns, such as its outline and size, but something the object shares with another object. For example the function of a knife emerges at the interface of the cutting edge of the knife and a surface that is cut. Cutting requires a cutting edge, a surface to be cut, and a force that pushes the cutting edge through the surface. Functions are often conceived of as entities that are superimposed on an object and that need to be inferred from the object itself. The reason one conceives of functions as superimposed entities is, perhaps, the striking uniry and boundedness of objects. This leads easily to the assumption that the outline of the object is all there is. However, as Gibson (1979) clearly argued years ago, an object is not just an oucline but a relation. It is a relation of surfaces. When we perceive the uniry and boundedness of an object, we perceive, in fact, a relation of surfaces. This is not the only relation that may be perceived directly. Objects do not populate an empty space. They are located in front of other surfaces and are supported from 
below by surfaces. The interface between the outline of objects and other surfaces forms other arrangements of surfaces. These arrangements have a shape, just as does the arrangement that forms the contours of an object. The difference between these is that the arrangement at the interface changes, whereas the arrangement that forms the contours of an object stays the same as the object is displaced. The shape at the interface specifies the objects' momentary function: the shape of the contours, the object's identity. Our research on infants' perception of objects indicates that perceiving an object's identity and perceiving its function are complementary. The one implies the other.

What does this view of the function of objects mean for manufactured products? It means that, when we deal with an object and its functions, we should realize that not just objects but relations are the units of perception, which may sometimes include several objects. When we measure affordances, we should focus not only on objects and the dimensions of those objects in relation to body dimensions, but also on dimensions of the interface of the objects and body dimensions, including body dimensions that arise due to implements. The directly perceivable relations at the interface of food and scoop is exploited in spoon use. Designers maintain that similar principles exist for the selection of the appropriate colors for products. To select the color for a chair in a room, it is important to look at the way the selected color for the chair will affect the colors presented in the surroundings. Changes in surrounding hues may make the initially preferred color less preferable.

\section{REFERENCES}

Gibson, J. J. (1986). The ecological approach to visual perception. Hillsdale, NJ: Lawrence Erlbaum Associates, Inc. (Original work published 1979)

Mark, L. S. (1987). Eyeheight-scaled information about affordances: A study of sitting and stair climbing. Joumal of Experimental Psychology: Human Perception and Performance.

Warren, W. H. (1984). Perceiving affordances: Visual guidance of stair climbing. Joumal of Experimental Psychology: Human Perception and Performance, 10, 683-703.

Warren, W. H., \& Whang, S. (1978). Visual guidance of walking through apertures: Body scaled information for affordances. Joumal of Experimental Psychology: Human Perception and Performance, $13,371-383$. 